\title{
Minimally invasive open lumbar discectomy: An alternative to microlumbar discectomy
}

\section{Devkota UP', Lohani $\mathrm{S}^{2}$, Joshi RM ${ }^{3}$}

${ }^{1}$ Consultant Neurosurgeon, ${ }^{2}$ Medical Officer, ${ }^{3}$ Registrar, National Institute of Neurological and Allied Sciences, Bansbari, Nepal

\begin{abstract}
Background: Lumbar disc surgery has come a long way since its first description by Dandy in $1929^{1}$. Evolving through the transdural approach and a laminectomy for the removal of a disc, it now surpasses the primal technique with essentially a minimally invasive procedure, an extradural approach without laminectomy ${ }^{2}$.

Objective: The objective of this study is to ascertain the effectiveness of Minimally Invasive Open Lumbar Discectomy in the treatment of lumbar disc prolapse.

Materials and methods: It is a descriptive study entailing the patients with paramedian or central disc prolapse at single or two consecutive lumbosacral levels undergoing surgery at the National Institute of Neurological and Allied Sciences, Bansbari, Nepal, over a period of one and a half years. Patients who underwent either laminectomy or bilateral fenestration were excluded. Results of surgery were measured prospectively in terms of primary outcome measure (outcome at six months follow up as measured with Prolo Functional and Economic Scale) and secondary outcome measures (radicular pain relief, mobilisation, complication, and residual disc).

Results: In the series of 137 consecutive patients, 120 fulfilled the criteria. $98.33 \%$ of patients had an improvement in the radicular pain and ambulation was commenced from the first post-operative day. There were three instances of inadvertent dural tear without fascicle injury, and one instance of residual disc requiring reoperation. At 6 months, 97.5 $\%$ had good to excellent (grade 4, or 5) results reaching the premorbid states in the Prolo Functional and Economic Scale.

Conclusion: The results of Minimally Invasive Open Lumbar Discectomy compare favourably with those of a microlumbar discectomy, and could therefore be an alternative to the latter in resource deprived circumstances.
\end{abstract}

Key words: Disc prolapse, Minimally Invasive Open Lumbar Discectomy, Microlumbar Discectomy

L umbar disc surgery has come a long way since its first description by Dandy in $1929^{1}$. Evolving through the transdural approach and a laminectomy for the removal of a disc, it now surpasses the primal technique with essentially a minimally invasive procedure, an extradural approach without laminectomy ${ }^{2}$. Treatment of herniated lumbar disc constitutes a major portion of neurosurgical practice and is performed by almost all neurosurgeons and orthopaedic surgeons with training in spinal surgery.

Lumbar disc disease forms the second most common cause for medically authorised absence from work ${ }^{3}$. Since the incidence of operable lumbar disc is considerably high, this surgery forms a major share of the average neurosurgeon's cases. However, the expertise to do lumbar surgery is vague and wide laminectomy for discs and lumbar canal stenosis is not accepted as the standard norm any more. Minimally invasive methods for lumbar disc are costly and require equipments which a neurosurgeon placed in an average institution in a developing country may not have access to.

The trend has been towards minimally invasive technique and microsurgical discectomy remains the gold standard ${ }^{2}$. Yet as a comparable alternative, we describe a simple technique of Minimally Invasive Open Lumbar Discectomy (MIOLD), which is the evolution of the senior author's experience in this surgery for over two decades.

Correspondence

Dr. Upendra Devkota

Consultant Neurosurgeon

Neurological and Allied Sciences

E-mail: devkotaup@neuro.org.np 
Materials and methods

Study Design: This is a prospective descriptive study conducted at the National Institute of Neurological and Allied Sciences, Kathmandu.

Sample Size: All lumbar disc cases who underwent MIOLD from August 2006 to January 2008 were evaluated.

\section{Exclusion Criteria}

- Patients who underwent laminectomy for disc removal.

- Patients with lumbar canal stenosis who underwent bilateral fenestration.

Tools and Techniques

Pertinent patient information was prospectively collected during the period of admission. Consent was received before surgery was undertaken. Most of the surgeries were done by the senior author himself or him as an assistant. Following discharge, patients were followed up to six months. Inquiry was made via telephone for those who did not show up in out-patient department. The outcome was measured using the Prolo Functional and Economic Scale (Table 1) ${ }^{4}$. All information collected were entered in computer database using Microsoft Excel 2007 for further analysis and graphic representation of the findings.

\section{Surgical procedure}

The patient is positioned prone in Jack-Knife position. Incision is marked based on the landmark of the highest point of the iliac crest corresponding to L4 spinous process. Cross-checking is done by palpating along the sacrum cranially and the first space felt is taken as the L5-S1 interspace. The incision is made $1 \mathrm{~cm}$ away from the midline to the side of the disc, usually $3 \mathrm{cms}$ long. The thoracolumbar fascia is divided along the line of incision and reflected medially with stay sutures. Paraspinal musculature is dissected off laterally till the medial facet and held back with William's retracter, thereby exposing the ligamentum flavum. This is followed by flavotomy, thus uncovering the thecal sac. A bit of lamina is taken to expose the root. The root as well as the thecal sac is retracted medially with two cotton pledgets to expose the disc. A number 4 Penfield dissector or a small curette is used to pierce the annulus after which the disc is delivered out. All the loose disc material is removed with pituitary rongeur and curetting the disc space is avoided as far as possible. The dorsolumbar fascia is closed with three stitches and the external wound is closed in layers without a drain.
Operating microscope is usually not required and an intra-operative X-ray localization is required only for levels higher than L4-5. Diathermy, either monopolar or bipolar is not routinely used.

Result

Over the mentioned period, altogether 137 patients were diagnosed to have lumbar disc disease requiring surgical intervention (Fig. 1). Seventeen of these were excluded from the study since they either underwent laminectomy or bilateral fenestration with nerve root decompression in addition to discectomy. Therefore, 120 cases with paramedian or central disc prolapse were subjected to analysis. Altogether 14 patients had multiple disc prolapsed, though only four of them underwent surgery at both levels as the other level was asymptomatic.

There were 82 males and 38 females with the ages ranging from 16-70 with a median age of 37. L5 radicular pain was the most common presentation (Fig 2) and accordingly L4-5, the most common level of disc prolapse (Fig 2). Radiological diagnosis was based on Magnetic Resonance Imaging (MRI) scans in 41 patients and Computed Tomography (CT) scans in 79 .

All patients underwent MIOLD as has been described by the senior author. There were 84 sequestrated discs and 36 contained discs. In five cases of L5- S1 discs, the flavotomy was repaired. Median operative time was 30 minutes. There were three instances of inadvertent dural tear without fascicle injury in very tight discs, all of which were repaired primarily. There was no instance of subsequent cerebrospinal fluid leak through the wound. There were five instances of superficial wound infection requiring no intervention. Patients had immediate relief of radicular pain with no neurological sequelae resulting from the surgery. Ambulation was commenced from first postoperative day in all, but delayed in three cases with dural tear and two with persistent pain. The average hospital stay was seven days.

We had a follow up in all patients in the outpatient department or through telephone. All the patients were evaluated on the basis of the Prolo Functional and Economic Scale (Table 2). At the end of six months, 118 were back to their original work, and 111 patients had excellent results (grade 5) reaching the premorbid states. One patient had a recurrence of symptoms and was diagnosed to have a residual disc at the same level and was operated upon. 
Table 1: Prolo Functional and Economic Rating Scale

\begin{tabular}{|l|l|}
\hline Status & Description \\
\hline Economic (activity) grade \\
\hline 1 & Complete invalid (worse) \\
\hline 2 & No gainful occupation (including housework or retirement activities) \\
\hline 3 & Working/ active but not at premorbid level \\
\hline 4 & Working/ active at previous level with limitation \\
\hline 5 & Working/ active at previous level without limitation \\
\hline Functional (pain) grade & \\
\hline 1 & Total incapacity (worse) \\
\hline 2 & Moderate to severe daily pain (no change) \\
\hline 3 & Low level of daily pain (improved) \\
\hline 4 & Occasional or episodic pain \\
\hline 5 & No pain \\
\hline
\end{tabular}

Table 2: Results based on primary and secondary outcome measures

\begin{tabular}{|c|c|c|}
\hline \multicolumn{2}{|c|}{ Primary Outcome Measure } & Results \\
\hline \multirow{5}{*}{$\begin{array}{l}\text { Prolo Functional and } \\
\text { Economic Scale at } 6 \\
\text { months }\end{array}$} & Grade 5 & $92.5 \%$ \\
\hline & Grade 4 & $5 \%$ \\
\hline & Grade 3 & $1.66 \%$ \\
\hline & Grade 2 & $0.83 \%$ \\
\hline & Grade 1 & $0 \%$ \\
\hline \multicolumn{3}{|c|}{ Secondary Outcome Measures } \\
\hline \multicolumn{2}{|c|}{ Post-operative radicular pain relief } & $98.33 \%$ \\
\hline \multicolumn{2}{|c|}{ Mobilization from first post-operative day } & $95.83 \%$ \\
\hline \multicolumn{2}{|c|}{ Operative complication } & $2.5 \%$ (Inadvertent dural tear) \\
\hline \multicolumn{2}{|c|}{ Post-operative complication } & $4.16 \%$ (Superficial wound infection) \\
\hline \multicolumn{2}{|c|}{ Residual disc } & $0.83 \%$ \\
\hline
\end{tabular}

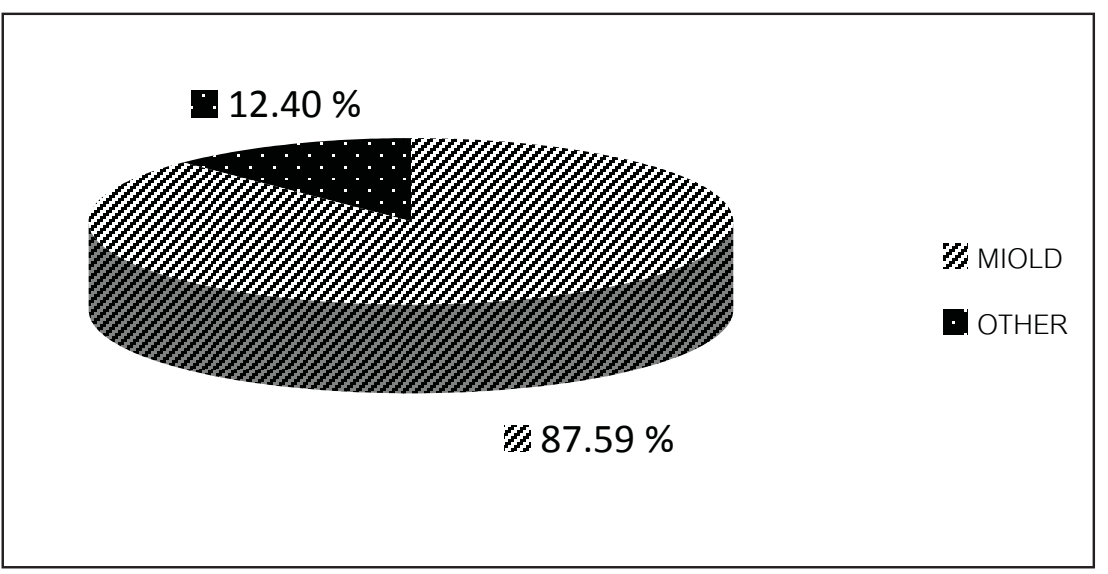

Fig 1: Graph displaying the surgical distribution of cases 


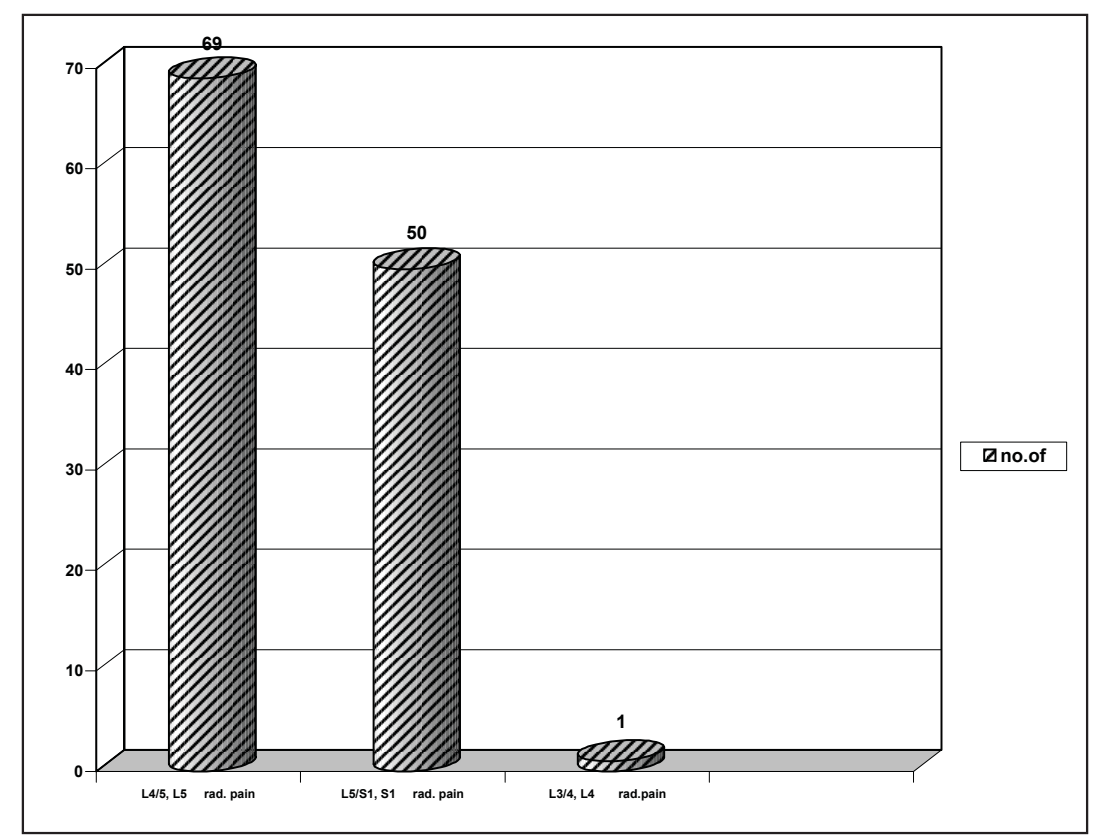

Fig 2: Graph displaying the level of disc herniation and corresponding radicular pain distribution

\section{Discussion}

Lumbar discectomy is a very common surgical procedure. There are many ways to do a lumbar discectomy, ranging from the standard laminectomy and discectomy to the endospine, chemonucleolysis and laser disc surgeries. The primary minimally invasive procedures for the treatment of lumbar disc disease include the following: 1) chemonucleolysis, introduced by Lyman Smith in $1964^{5}$; 2) percutaneous manual nucleotomy, introduced by Hijikata in $1975^{6}$; 3) microdiscectomy, first performed by Yasargil in $1968^{7}$; 4) automated percutaneous lumbar discectomy, introduced by Onik in $\left.1984^{8} ; 5\right)$ laser discectomy, first performed by Ascher and Choy in $1987^{9}$; 6) endoscopic discectomy, first used by Schreiber and Suezawa in 1986 and improved by Mayer, Brock, and Mathews ${ }^{10,11,12}$; 7) microendoscopic discectomy, introduced by Smith and Foley in 1995 ${ }^{13}$; and 8) intradiscal electrothermy, first reported by Saal and Saal in $2000^{14}$.

The results of these surgeries vary. While catching up with the trend of minimally invasive technique, with its considerable benefits in terms of small incision, decreased trauma to the lumbar musculature, easier identification of deep-seated structures, minimal traumatic manipulation of neural structures, and direct view into the disc, microsurgical discectomy is now the gold standard treatment ${ }^{2}$. Outcomes of microdiscectomy are consistently impressive, with success rate ranging from 84 to $98.5 \%{ }^{15-22}$.

In the microlumbar discectomy series of Maroon JC, patients were urged to walk immediately and were discharged within 23 hours (either the same day or the following morning) in $95 \%$ of the $\operatorname{cases}^{20}$. The average operative time was 30 to 60 minutes. Rates of complications such as dural tears, nerve root injury, and discitis were less than $1.5 \%$. Long-term rates of reoperations at the same level were less than $5 \%$. Approximately $90 \%$ of patients experienced good to excellent pain relief. The result of the present series compares favourably with that of Maroon's.

As per the rates of complication, long term rates of reoperation and outcome assessment, our results are on a par with the results of Maroon's series ${ }^{20}$.

The hospital stay in this series was seven days in average, mainly due to the fact that patients from outside the Kathmandu valley seldom found a decent place to stay outside the hospital and wanted to stay on till the suture removal. The author has however proved the feasibility of day care MIOLD in his previous communication ${ }^{23}$.

Use of X-ray for localisation of disc level, arrangement of microscopes and performance under microscope inevitably prolongs the duration of surgery. Since MIOLD doesn't need any of these, it offers a considerable advantage in terms of the duration of surgery too. Our average operating time was only 30 minutes.

CT scans were opted in majority of the cases primarily due to the non-availability of MRI. Since discs could be well appreciated in the CT scans, MRI was reserved for 
cases with non-diagnostic CT scan or those with less discrete history and root signs.

Our previous series of 411 patients has also established the effectiveness of MIOLD. In that particular series, $72.7 \%$ of the patients were fit for day care surgery, with $85.6 \%$ achieving excellent result in terms of Hudgin's outcome criteria ${ }^{23}$.

\section{Conclusion}

The result of MIOLD compares favourably with that of microdiscectomy. In addition, it requires no microscope and rare use of radiological localisation, and hence less resource consuming. Therefore in situation where a surgeon may either have no facility for microdiscectomy or is not trained enough to perform that, MIOLD may be a good alternative rather than reverting back to more invasive standard laminectomy and discectomy.

\section{References}

1. Dandy WE. Loose Cartilage from intervertebral disc simulating tumor of the spinal cord. Clin Orthop Relat Res. 1989;238:4-8.

2. Maroon JC. Current concepts in minimimally invasive discectomy. Neurosurgery. 2002;51:S137-45.

3. Cypress BK. Characteristics of physician visits for back symptoms: A National Perspective. Am J Public Health. 1983;73:389-95.

4. Prolo DJ, Oklund SA, Buther M. Toward uniformity in evaluating results of lumbar spine operations: a paradigm applied to posterior interbody fusions. Spine. 1986;11:601-6.

5. Smith L. Enzyme dissolution of the nucleus pulposus in humans. JAMA. 1964;187:137-40.

6. Hijikata S, Yamgishi M, Nakayama T, Oomori K. Percutaneous discectomy: A new treatment method for lumbar disc herniation. J Toden Hosp. 1975;5:5-13.

7. Yasargil MG. Microsurgical operation for herniated disc. In: Wullenweber R, Brock M, Hamer J, Klinger M, Spoerri O (editors). Advances in Neurosurgery. Philadelphia: Springer-Verlag; 1977. p. 81.

8. Onik G, Helms CA, Ginsberg L, Hoaglund FT, Morris J. Percutaneous lumbar discectomy using a new aspiration probe. AJNR Am J Neuroradiol. 1985;6:290-3.

9. Choy DS, Case RB, Fielding W, Hughes J, Liebler W, Ascher P. Percutaneous laser nucleolysis of lumbar disc. N Engl J Med. 1987;317:771-2.
10. Schreiber A, Suezawa Y. Transdiscoscopic percutaneous nucleotomy in disc herniation. Orthop Rev. 1986;15:35-8.

11. Mayer HM, Brock M. Percutaneous endoscopic discectomy: Surgical technique and preliminary results compared to microsurgical discectomy. J Neurosurg. 1993;78:216-25.

12. Mathews HH. Transforaminal endoscopic microdiscectomy. Neurosurg Clin N Am. 1996;7:59-63.

13. Smith MW, Foley KT. Microendoscopic Discectomy (MED): The first 100 cases. $48^{\text {th }}$ Annual Meeting of the Congress of Neurological Surgeons; 1998.

14. Saal JS, Saal JA. Management of chronic discogenic low back pain with a thermal intradiscal catheter: A preliminary study. Spine. 2000;25:382-8.

15. Andrews DW, Lavyne MH. Retrospective analysis of microsurgical and standard lumbar discectomy. Spine. 1990;15:329-35.

16. Caspar W, Campbell B, Barbier DD, Kretschummer R, Gotfried Y. The Caspar microsurgical discectomy and comparison with a conventional standard lumbar disc procedure. Neurosurgery. 1991;28:78-87.

17. Ebeling U, Reichenberg W, Reulen HJ. Results of microsurgical lumbar discectomy: Review of 485 patients. Acta Neurochir (Wien). 1986;81:45-52.

18. Heary R, Cacnio E, Black M. Microendoscopic Discectomy (MED) Learning curve and pitfalls in the initial 25 cases. $49^{\text {th }}$ Annual Meeting of the Congress of Neurological Surgeons; 1999.

19. Hudgins WR. The role of microdisectomy. Orthop Clin North Am. 1983;14:589-603.

20. Maroon JC, Abla A. The microlumbar discectomy. Clin Neurosurg 1986;33:407-17.

21. Silvers HR. Microsurgical versus standard lumbardiscectomy. Neurosurgery. 1988;22:83741.

22. Wilson DH, Kenning J. Microsurgical lumbar discectomy: Preliminary report of 83 consecutive cases. Neurosurgery. 1979;4:137-40.

23. Devkota UP, Bista P. Day case open lumbar discectomy: Proceedings of the 139th Meeting of the Society of British Neurological Surgeons; 2001 Sep 5-7; Thames, The UK. Br J Neurosurg (supplement) 2002;16:403-17. 